\title{
EVALUATION OF CARBON ASSISTED Q SWITCHED ND-YAG LASER TREATMENT FOR INFLAMMATORY ACNE: SPLIT FACE COMPARATIVE STUDY.
}

\author{
By \\ Nesma Ghareeb Nagdy Amer, Osama Magdy El-Shahat Sayed Ahmed, \\ Ibraheem Abd El-Salam Abd El-Kareem* and Hassan Abou-Khodair \\ Mohamed
}

Department of Dermatology, Venereology and Andrology, Faculty of Medicine, Al-Azhar University, Damietta and cairo*

Corresponding Author: Nesma Ghareeb Nagdy Amer, Phone: +201005055549,

E-mail: nesma.ghareeb2020@gmail.com

\begin{abstract}
Background: There are behavioral/emotional and physical/psychological effects caused by acne. Q-switched $\mathrm{Nd}$ : YAG laser with topical carbon suspension could provide satisfactory clinical results for the treatment of inflammatory acne.

Objective: To evaluate the efficacy of Carbon Assisted Q-Switched Nd:YAG Laser Treatment for inflammatory acne.

Place of study: Al-Hussein University Hospital, Cairo, Egypt.

Patients and methods: This was a prospective split-face simple randomized clinical trial carried out during the period from October 2019 to March 2021 including 20 patients of all ages and both sexes with clinical diagnosis of inflammatory acne.

Results: The counts of all types of active acne lesions in Carbon side were steadily reduced from the first session. Eight weeks after completing the sixth session, the improvement rate of the inflammatory lesions was $32 \%$ on average $40 \%$ of patients had a poor response, $20 \%$ had moderate response, and $40 \%$ had a good response. Nobody reported excellent response. The effective rate (rate of success) was $40 \%$. The other side showed low response rate that was $8.6 \%$ on average where $70 \%$ had a poor response. Only $30 \%$ (6 patients) had a moderate response, and nobody reported excellent response. The effective rate (rate of success) was $0 \%$. There was a statistically significant difference between both sides regarding improvement, acne count and patient satisfaction, and no severe side effects were reported.

Conclusion: Carbon assisted Q switched Nd-YAG Laser has a safe and fair effect in treating active inflammatory acne, while Q switched Nd-YAG Laser alone has aweak effect in treating active inflammatory acne indicating that Carbon lotion augmented the effect of the Laser.
\end{abstract}

Keywords: Carbon assisted, Q switched Nd-YAG LASER, acne, inflammatory acne.

\section{INTRODUCTION}

Acne is a very common skin disease. The prevalence among adolescent is $80 \%$ or more (Minh et al., 2019). Among them $80 \%$ are teenagers (Costa et al., 2018).

The pathogenesis of acne vulgaris is multifactorial, involving 
hyperkeratinization of the pilosebaceous duct, ductal colonization with Propionibacterium acnes (P. acnes), increased sebum production, hormonal factors, and diet. In addition, there is a recently increased focus on the chronic inflammation and inflammatory cytokine cascades contributing in the pathogenesis of an acne lesion (Eichenfield et al., 2015).

Approximately, $80 \%$ to $90 \%$ of teenagers in the Western world experience behavioral or emotional and physical or psychological effects caused by acne (Ettel et al., 2017).

Traditional treatments for AV include topical and oral antibiotics, topical keratolytics, hormonal agents, and topical and oral retinoids. Increased resistance to traditional treatment options, combined with undesirable side effects, has given way to alternative therapies. Most promising over recent years are lightbased therapies (Handler et al., 2016).

Many laser and light-based devices (range from the visible spectrum to the infrared wavelengths) have been shown to be effective in the treatment of acne. The mechanism of action of these devices in the treatment of acne is not completely understood but mostly due to the creation of photo-thermal and/or photo-chemical reactions resulting in a positive impact to the pilosebaceous unit and factors affecting (Kim and Del Rosso, 2010).

In this study, we aimed to evaluate the efficacy of Carbon Assisted QSwitched Nd:YAG Laser Treatment for inflammatory acne.

\section{PATIENTS AND METHODS}

This prospective split-face simple randomized clinical trial was carried out during the period from October 2019 to March 2021. The study subjects were recruited from the outpatient clinic of $\mathrm{Al}-$ Hussein University Hospital, Cairo, Egypt. The research ethics committee of our University approved the study protocol, and all participants in the study provided informed written consents before inclusion. The study included 20 patients of all ages and both sexes with clinical diagnosis of inflammatory acne.

Exclusion criteria: Pregnant and lactating women, patients with prior therapy with isotretinoin within last six months, patients with systemic antibiotic therapy (for any indication) within last one month, patients who used topical acne preparation or intralesional steroid injection within last one month.

All participants underwent detailed history taking, clinical examination and not allowed to use any systemic, topical, or phototherapy-based acne treatment during the course of the study. The patients were simple randomized to receive laser treatment with Carbon on one half of the face (referred to as Carbon side), whereas the other side of the face received only laser therapy without Carbon (referred to as other side).

Before each session, the patient's face has been cleansed with soap and water. after drying the face, topical anaesthetic cream has been applied for 20 to 30 minutes, then any excess anaesthetic cream has been removed, and a topical purified carbon lotion has been applied over the Carbon side of the face and has 


\section{EVALUATION OF CARBON ASSISTED Q SWITCHED ND-YAG LASER... ${ }^{751}$}

been allowed to penetrate the skin and follicles for 15 to 20 minutes then any excess carbon lotion has been wiped off the face with alcohol swabs.

Q-switched Nd:YAG mode laser (Quanta Q plus laser system) was used as a source for laser. Starting with the Carbon side of the face, the laser was set to the initial fluence of $1.5 \mathrm{~J} / \mathrm{cm} 2$ that was increased to $2.5 \mathrm{~J} / \mathrm{cm} 2$ as close as possible, using a 6-mm hand piece which took approximately 5 minutes. The same treatment protocol was carried out in the same order to the other side of the face. After 10 minutes, the treated areas were gently thoroughly cleansed with a nonsoap neutral cleanser and cotton pads soaked in cold water, and then patted dry with soft gauze pads then ice packs were applied. After treatment, daily application of a hypoallergenic moisturizing skin cream containing a UVA/B sunscreen (SPF 50) was recommended. Topical antibiotic was applied for 3 days. The patient was treated for six sessions with a 2 weeks interval.

Clinical assessment and standardized digital photographs were conducted at baseline, before each session and 8 weeks after the last session using identical camera settings and lighting conditions. To minimize the bias, one practitioner performed all the laser treatments and another two experienced independent Dermatologists not involved in the study performed the assessments including acne counts and acne severity.

Assessment of acne severity was conducted according to Hayashi et al. (2008) who used photographs and inflammatory eruption counting to classify acne into four groups.

The participants were asked about their satisfaction degree using a 5-point scale questionnaire $(0=$ very unsatisfied, $5=$ very satisfied) before first session and 8 weeks after the last session.

During and after each session and eight weeks after the last session, side effects were evaluated by asking the patients if they had experienced any problems such as pain, and by assessing the skin responses, including erythema, odema, exudation, pin-point bleeding, crusting, hyperpigmentation, hypopigmentation and acneiform eruption.

\section{Statistical Analysis:}

All data were collected, tabulated and statistically analyzed using SPSS 26.0 for windows (SPSS Inc., Chicago, IL, USA) and Microsoft Excel 2016. Descriptive statistics were performed for all study variables with a normality test for all quantitative variables. Data were tested for normal distribution using the Shapiro Wilk test. Qualitative data were represented as frequencies and relative percentages. Quantitative data were expressed as mean \pm SD (Standard deviation), Mann-Whitney U-test was used to compare numerical variables, range, median and interquartile range (1QR) between 2 groups. The results of data analysis were presented in the text, tables or figures as appropriate. Differences have been considered significant when probability (p) value < 0.05 . 


\section{RESULTS}

The study included 20 patients of all ages and both sexes with clinical diagnosis of inflammatory acne (Table 1).

\section{Table (1): Demographic data of the studied group}

\begin{tabular}{|c|c|c|}
\hline Variable & \multicolumn{2}{|c|}{$\begin{array}{l}\text { The study group } \\
\qquad(\mathrm{n}=20)\end{array}$} \\
\hline $\begin{array}{c}\text { Age: } \\
\text { Mean } \pm \text { SD } \\
\text { Median (IQR) } \\
\text { Range }\end{array}$ & \multicolumn{2}{|c|}{$\begin{array}{c}22.45 \pm 4.48 \\
22(19-25.75) \\
16-31\end{array}$} \\
\hline & No & $\%$ \\
\hline $\begin{array}{c}\text { Age: }(\text { years) } \\
15-19 \text { years } \\
20-24 \text { years } \\
25-30 \text { years } \\
\geq 30 \text { years }\end{array}$ & $\begin{array}{l}6 \\
7 \\
5 \\
2\end{array}$ & $\begin{array}{l}30.0 \% \\
35.0 \% \\
25.0 \% \\
10.0 \%\end{array}$ \\
\hline & No & $\%$ \\
\hline $\begin{array}{l}\text { Sex: } \\
\text { Male } \\
\text { Female }\end{array}$ & $\begin{array}{c}1 \\
19\end{array}$ & $\begin{array}{c}5.0 \% \\
95.0 \%\end{array}$ \\
\hline
\end{tabular}

IQR: interquartile range

The facial acne was severe in $55 \%$ of patients and moderate severity in $45 \%$.

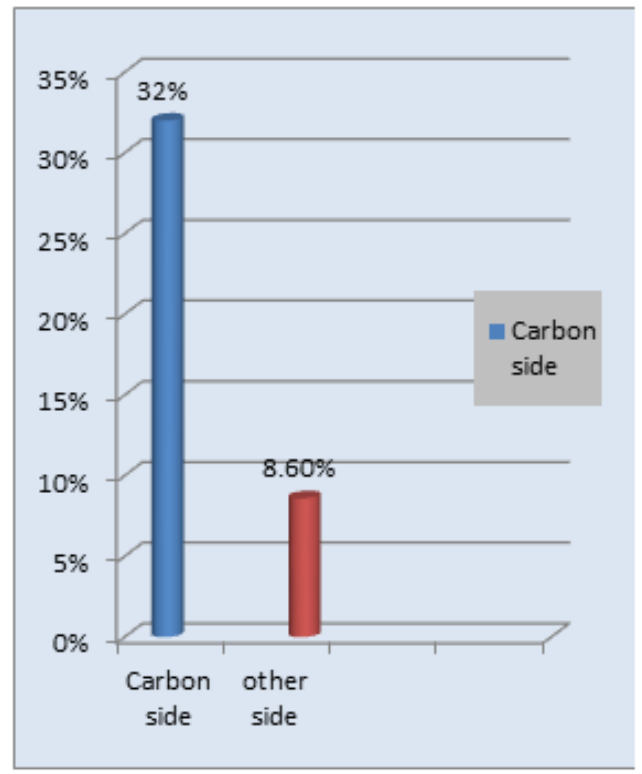

Figure (1): Mean improvement in both sides.

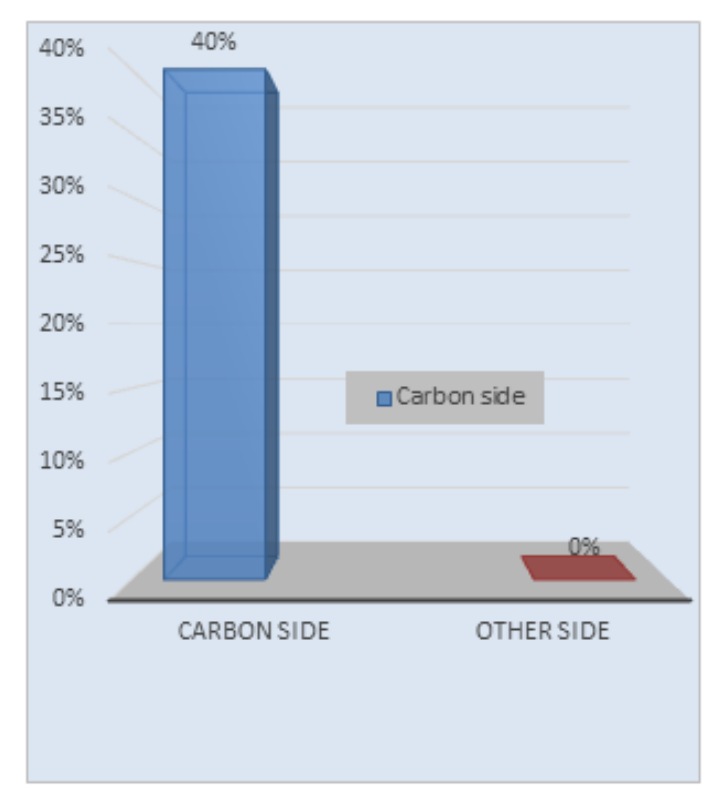

Figure (2): the effective rate in both sides. 
The Carbon side: The counts of all types of active acne lesion were steadily reduced from the first session. eight weeks after completing the sixth session, the improvement rate of the inflammatory lesions was $32 \%$ on average. Investigators determined that 8 out of $20(40 \%)$ patients was rated as having poor (less than $30 \%$ ) improvement and 4 out of 20 (20\%) patients was rated as having moderate (30\% to $59 \%$ ) improvement and 8 out of $20(40 \%)$ patients rated as having good $(60 \%$ to $89 \%)$ improvement. Nobody reported excellent improvement (more than $90 \%$ ). The effective rate was $40 \%$ Table (2).

The Other side: eight weeks after completing the sixth session, the improvement rate of the inflammatory lesions was $8.6 \%$ on average. 14 out of 20 $(70 \%)$ patients were rated as having poor (less than 30\%) improvement, only 6 out of $20(30 \%)$ patients rated with moderate (30\% to $59 \%)$ improvement. Nobody reported improvement of more than 59\%. The effective rate was (0\%) Table (2).

Table (2): Summarized the clinical outcomes

\begin{tabular}{|c|c|c|c|}
\hline Variables & & \multicolumn{2}{|c|}{$\begin{array}{l}\text { The study group } \\
(\mathrm{n}=\mathbf{2 0})\end{array}$} \\
\hline \multirow{7}{*}{$\begin{array}{c}\text { Degree of improvement on } \\
\text { Carbon side }\end{array}$} & $\begin{array}{c}\text { Mean } \pm \text { SD } \\
\text { Median } \\
\text { Range }\end{array}$ & \multicolumn{2}{|c|}{$\begin{array}{c}32 \% \pm 0.21 \\
30 \% \\
0 \%-70 \%\end{array}$} \\
\hline & & $\mathrm{N}$ & $\%$ \\
\hline & Poor & 8 & $40.0 \%$ \\
\hline & moderate & 4 & $20.0 \%$ \\
\hline & Good & 8 & $40.0 \%$ \\
\hline & Excellent & 0 & $0.0 \%$ \\
\hline & \multicolumn{2}{|c|}{ The effective rate } & $40 \%$ \\
\hline \multirow{7}{*}{$\begin{array}{c}\text { Degree of improvement } \\
\text { onother side }\end{array}$} & $\begin{array}{c}\text { Mean } \pm \text { SD } \\
\text { Median } \\
\text { Range }\end{array}$ & \multicolumn{2}{|c|}{$\begin{array}{c}8.6 \% \pm 0.07 \\
2.8 \% \\
0-31 \%\end{array}$} \\
\hline & & $\mathrm{N}$ & $\%$ \\
\hline & Poor & 14 & $70.0 \%$ \\
\hline & moderate & 6 & $30.0 \%$ \\
\hline & Good & 0 & $0.0 \%$ \\
\hline & Excellent & 0 & $0.0 \%$ \\
\hline & \multicolumn{2}{|c|}{ The effective rate } & $0.0 \%$ \\
\hline
\end{tabular}

There was no statistical significant difference between both sides regarding the number of lesions before treatment. The Carbon side showed an improvement at the final eight weeks follow up visit compared to before the treatment. The counts were decreased by $43.47 \%$ (from $23 \pm 9.4)$ to $(13 \pm 4.4)$ while in Other side the counts were only decreased by $13.44 \%$ from $(18.6 \pm 6.48)$ to $(16 \pm 4.2)$ Figure (3).the difference between both sides regarding number of lesions eight weeks after last session was statistically significant $(\mathrm{P}=0.03)$. and there was high statistical significant difference between both sides regarding improvement score as the Carbon side showed high improvement score compared to other side $(\mathrm{p}<0.001)$.

Eight weeks after the last session, the satisfaction questionnaire indicated that $8 / 20(40 \%)$ subjects were satisfied with their response in Carbon side while only one patient $(5 \%)$ was satisfied with response in other side and the difference was statistically significant $(P=0.04)$. 
NESMA GHAREEB et al.,

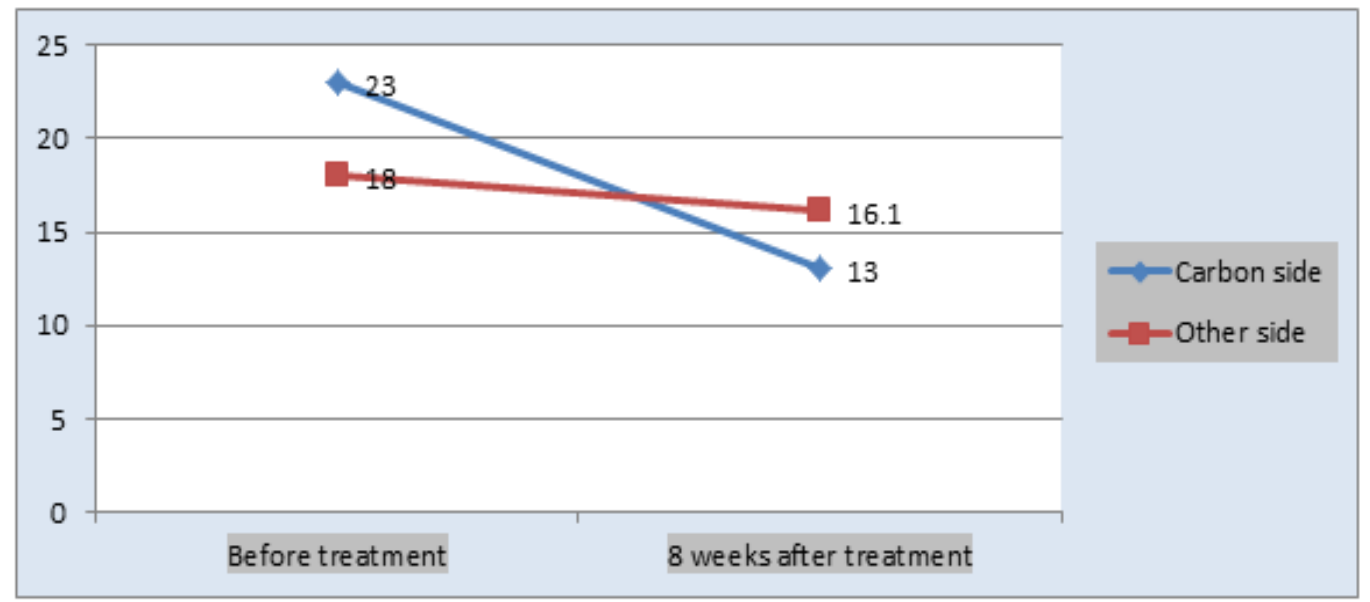

Figure (3): Mean number of lesions before and after treatment in both sids.

No severe side effects were reported. All patients reported mild tolerable pain during the procedure, mild erythema that disappeared 3 to 4 hours later. No edema, exudation, bleeding, crusting,
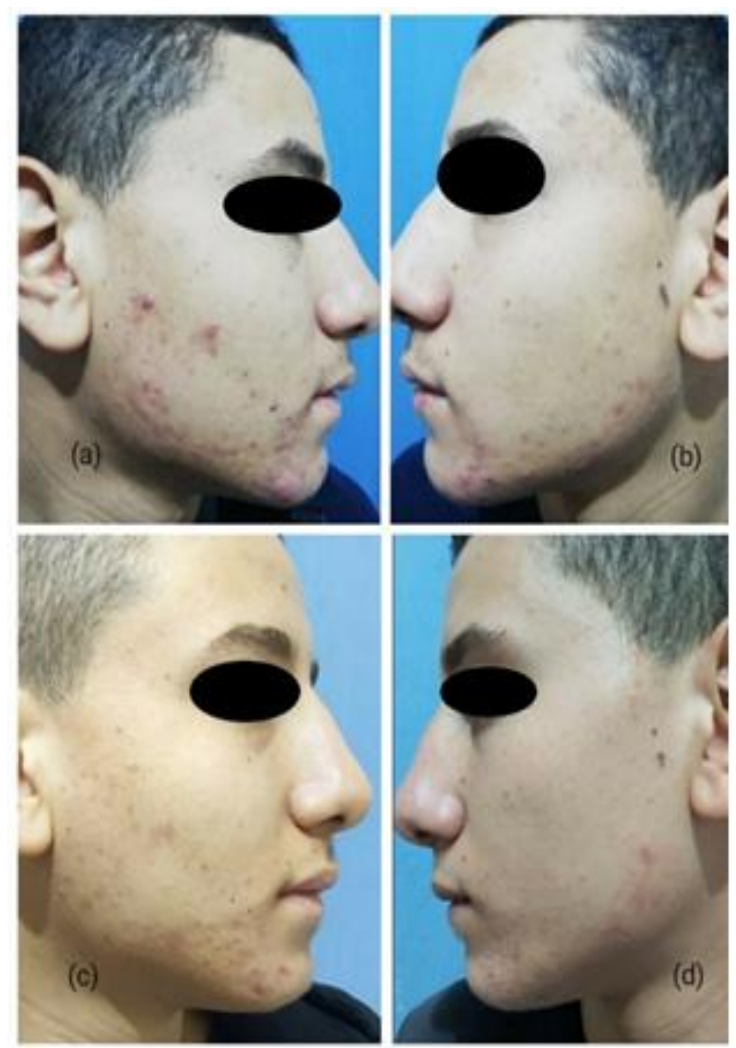

hyperpigmentation, hypopigmentation or other side effects were seen. All patients were able to return to their work and resume normal daily activity on the day of treatment.

Figure (4):A 19 years old male with acne vulgaris: (a) Carbon side at baseline, (b) Other side at baseline, (c) Carbon side 8 weeks after last session, (d) Other side 8 weeks after last session. 


\section{EVALUATION OF CARBON ASSISTED Q SWITCHED ND-YAG LASER... ${ }^{75}$}

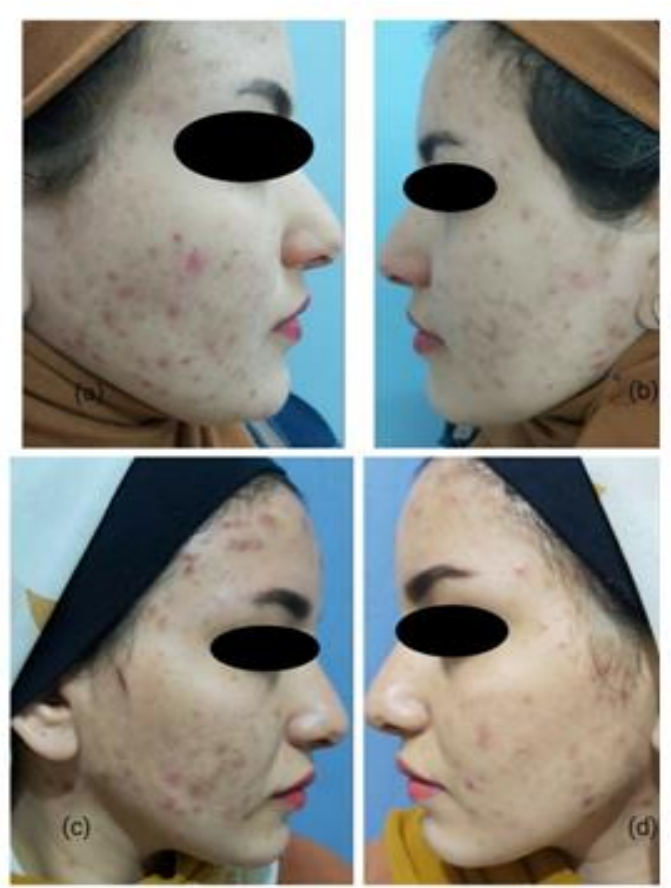

\section{DISCUSSION}

The Q-switched 1064-nm Nd:YAG laser is not usually used for acne treatment, but careful manipulation of the beam parameters or combination with an exogenous artificial chromophore, such as topical carbon lotion serving as a photoenhancer, has been associated with significant improvements in acne (Jung et $a l ., 2012$ ). These results might be due to thermal influences to the pilo-sebaceous unit and P. acnes, and to a decreased cytokine-mediated inflammatory cascade that likely plays a large role in the initiation of an acne lesion (Kircik 2016). The carbon suspension serves as an exogenous chromophore. In addition to destroying the sebaceous gland, the laser acts to modulate and decrease inflammation.

Taking these findings into consideration, we believed that the mechanisms associated with carbon assisted Nd:YAG laser treatment for skin
Figure (5):A 22 years old female with acne vulgaris: (a) Carbon side at baseline, (b) Other side at baseline, (c) Carbon side 8 weeks after last session, (d) Other side 8 weeks after last session.

rejuvenation could be equally applicable to the treatment of acne lesions.

Our research is unique in that we studied the effect of Q switched Nd:YAG Laser either alone or Carbon assisted for treatment of inflammatory acne in a split face study.

The counts of all types of active acne lesion in Carbon side were steadily reduced from the first session. Eight weeks after completing the sixth session, the improvement rate of the inflammatory lesions was $32 \%$ on average.

Investigators determined that $40 \%$ of patients had a poor response and $20 \%$ had moderate response and $40 \%$ had a good response. Nobody reported excellent response. The effective rate was $40 \%$.

The other side showed low response rate that was $8.6 \%$ on average where $70 \%$ had a poor response, only $30 \%$ had a moderate response. Nobody reported 
excellent response. The effective rate was $0 \%$.

There was no statistical significant difference between both sides regarding number of lesions before treatment. However, there was an improvement after eight weeks follow up compared to before the treatment in Carbon side where the counts were decreased by $43.47 \%$, while in other side the counts only decreased by $13.44 \%$ and the difference between them was statistically significant.

There was a high statistical significant difference between both sides regarding improvement score as the Carbon side showed high improvement score compared to other side.

The satisfaction questionnaire indicated that $40 \%$ subjects were satisfied with their degrees of acne in Carbon side, while only one patient (5\%) was satisfied with results in other side and the difference was statistically significant.

Our study didn't show high success rate especially in the side with only Qswitched laser (without Carbon).

Other previous studies showed higher success rate, that could be because they used either dual mode (long-pulsed and Qswitched) 1,064-nm Nd:YAG laser or Nd:YAG laser combined with PDL.

Also, the results could affect the severity of acne as all cases in our study ranged from moderate to severe form; a better result could be come out in mild cases.

Jung et al. (2016) studied a dual mode (quasi-long pulse and Q-switched mode) $1064 \mathrm{~nm}$ laser in 22 patients with facial acne. In that study, mean inflammatory acne lesion count was reduced at eight week follow-up by $58.6 \%$, and the study also reported sebum output reduction and inflammatory cell and cytokine reductions.

Bakus et al. (2018) showed that combination long-pulsed and Q-switched 1,064-nm Nd:YAG lasers were highly effective in treating moderate to severe inflammatory acne. Significant reductions were observed in the acne lesion count immediately after treatment $(81 \%$ reduction) and $86 \%$ at 2 years follow up.

In a case report by Chun et al. (2011), six treatments were given, 2 weeks apart of Carbon Assisted Q-Switched Nd:YAG laser for severe inflammatory acne, more than $90 \%$ clearance of inflammatory lesions was achieved by the sixth treatment. At the eight weeks follow up after the last treatment, long-lasting improvements in the patient's acne were noted.

In our study, no severe side effects were reported. Almost all patients reported mild but tolerable pain during the procedure, mild transient erythema that disappeared 3 to 4 hours later. other studies reported the same safety indicating that the Q switched Nd-YAG laser either alone or Carbon assisted is relatively safe in treating active acne.

Our study was novel and unique; however, there were several limitations. The study was limited by its small sample size and short follow up times.

\section{CONCLUSION}

Carbon assisted Q switched Nd:YAG laser has a safe and fair effect in treating active inflammatory acne and it reduce the inflammatory response. While Q switched 
Nd-YAG laser alone has a weak effect in treating active inflammatory acne indicating that Carbon lotion augmented, the effect of the $\mathrm{Q}$ switched $\mathrm{Nd}$ :YAG laser.

\section{Conflict of interest: None.}

\section{REFERENCES}

1. Bakus, A. D., Yaghmai, D., Massa, M. C., Garden, B. C.and Garden, J. M. (2018): Sustained benefit after treatment of acne vulgaris using only a novel combination of long-pulsed and Q-switched 1064-nm Nd: YAG lasers. Dermatologic Surgery, 44(11), 1402-1410.

2. Chun, S. I. and Calderhead, R. G. (2011): Carbon assisted Q-switched Nd: YAG laser treatment with two different sets of pulse width parameters offers a useful treatment modality for severe inflammatory acne: a case report. Photomedicine and Laser Surgery, 29(2): 131-135.

3. Costa, C. S., Bagatin, E., Martimbianco, A. L. C., da Silva, E. M., Lúcio, M. M., Magin, P. and Riera, R. (2018): Oral isotretinoin for acne. Cochrane Database of Systematic Reviews, (11): 225-231.

4. Eichenfield, L. F., Del Rosso, J. Q., Mancini, A. J., Cook-Bolden, F., Desai, S., Weiss, J., and Kircik, L. (2015): Evolving perspectives on the etiology and pathogenesis of acne vulgaris. Journal of Drugs in Dermatology: JDD, 14(3): 263-272.
5. Ettel, D. L., LaManno, L. R., Neyra, S. A., Ettel, W. J., Ettel III, G. L., and Mitchell, M. K. (2017): Teens and technology transforming acne treatment. The Permanente journal, (21): 765-769.

6. Handler, M. Z., Bloom, B. S. and Goldberg, D. J. (2016): Energy-based devices in treatment of acne vulgaris. Dermatologic Surgery, 42(5): 573-585.

7. Jung, J. Y., Hong, J. S., Ahn, C. H., Yoon, J. Y., Kwon, H. H. andSuh, D. H. (2012): Prospective randomized controlled clinical and histopathological study of acne vulgaris treated with dual mode of quasi-long pulse and Q-switched 1064-nm Nd: YAG laser assisted with a topically applied carbon suspension. Journal of the American Academy of Dermatology, 66(4): 626-633.

8. Kim, G. K. and Del Rosso, J. Q. (2010): Laser and light-based therapies for acne vulgaris: a current guide based on available data. Journal of Drugs in Dermatology: JDD, 9(6), 614-621.

9. Kircik, L. H. (2016): Advances in the Understanding of the Pathogenesis of Inflammatory Acne. Journal of Drugs in Dermatology: JDD, 15(1 Suppl 1): s7-10.

10. Minh, P. P. T., Bich, D. D., Van Nguyen ThiHai, T. N., Van, V. T. C., Khang, T. H., Gandolfi, M., ... and Lotti, T. (2019): Microneedling therapy for atrophic acne scar: effectiveness and safety in Vietnamese patients. Open access Macedonian Journal of Medical Sciences, 7(2): 293-297. 
تقييم ليزر الياج البالغ القوة المساعد بماسك الكربون فى علاج

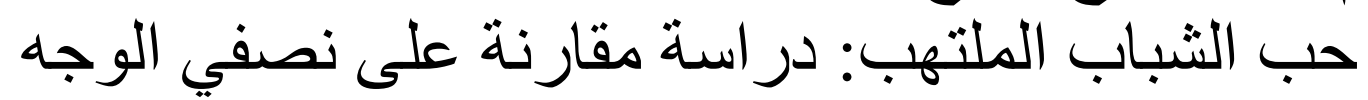
نسمة غريب نجدى عامر، أسامه مجدي الثحات سيداحمد، ابراهيم محمد عبدالسلام عبدالكريم*, حسن أبو خضير محمد

قسم الأمراض الجلدية و التناسلية وأمراض الذكورة، كلية الطب (دمياط ـ القاهرة*)، جامعة الازهر E-mail: nesma.ghareeb2020@gmail.com

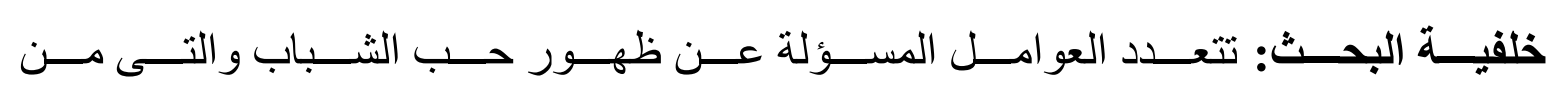

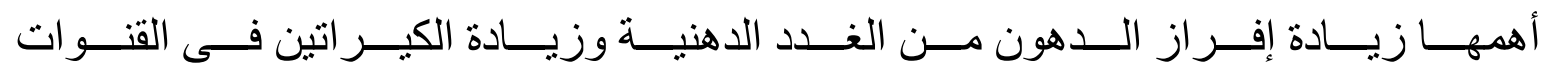

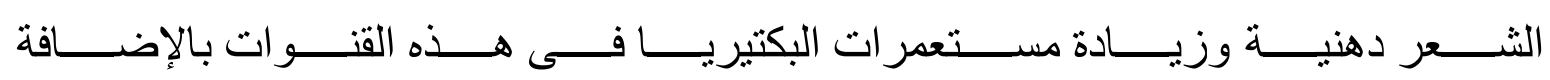

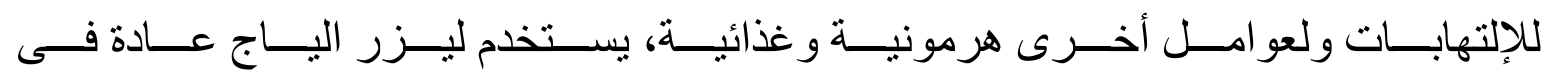

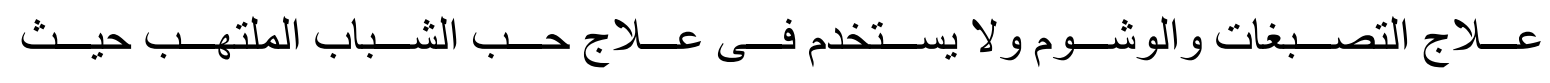

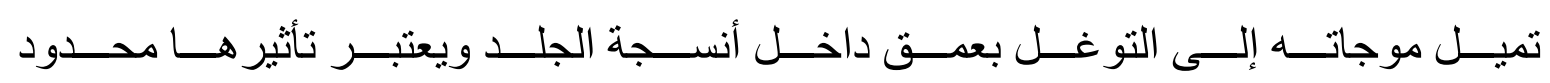

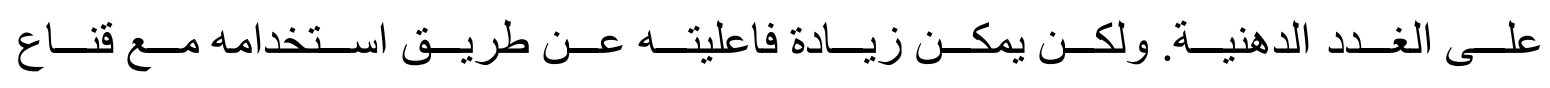

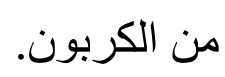

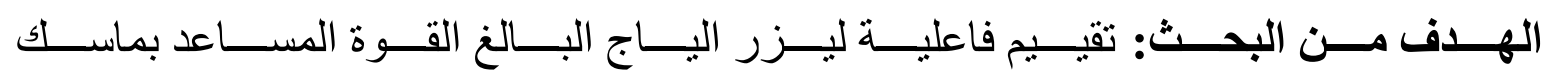
الكربون فى علاج حب الثنباب الملتوب. مكان البحث: مستثثفى الحسين الجامعى، القاهرة.

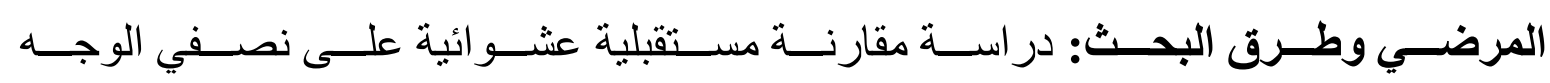

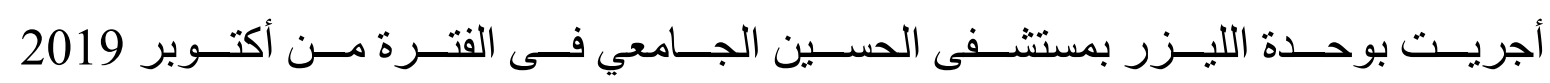

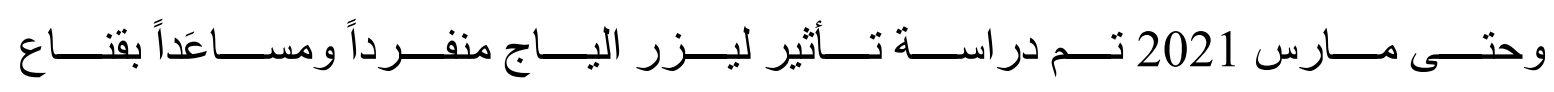
الكربون على عشرين مريض يعانون من حب الثباب الملتهب.

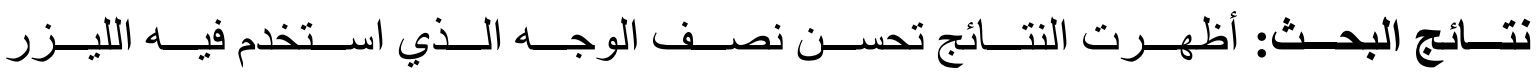

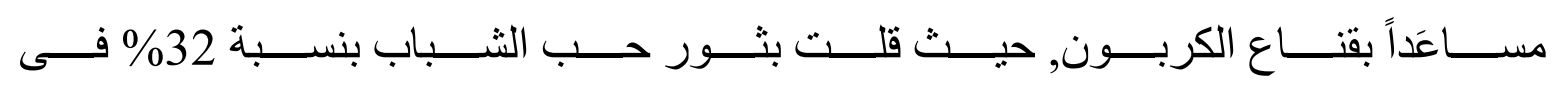

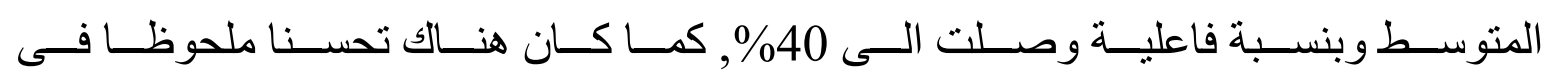


EVALUATION OF CARBON ASSISTED Q SWITCHED ND-YAG LASER... 759

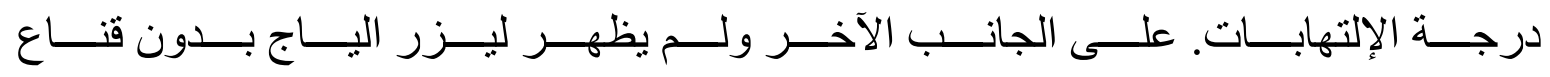

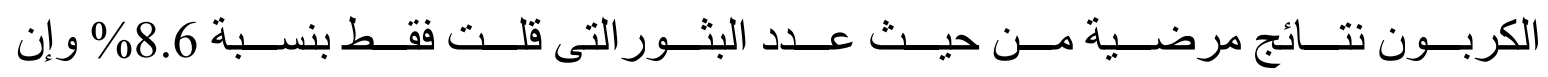

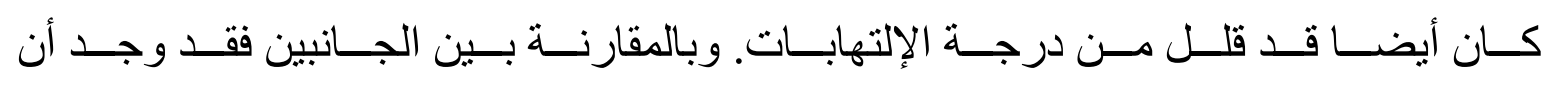

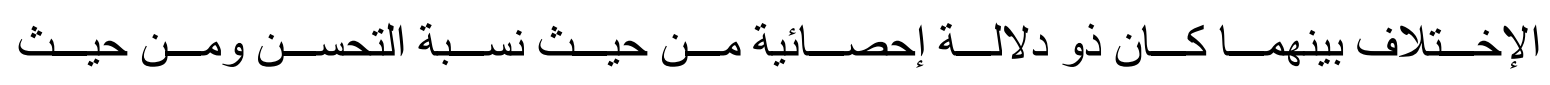

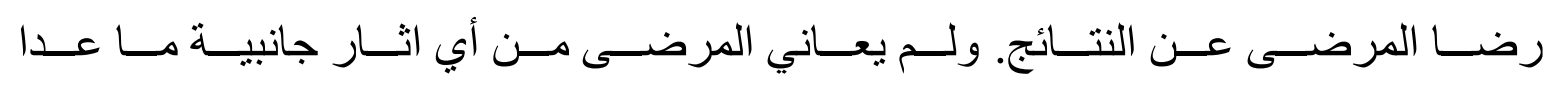

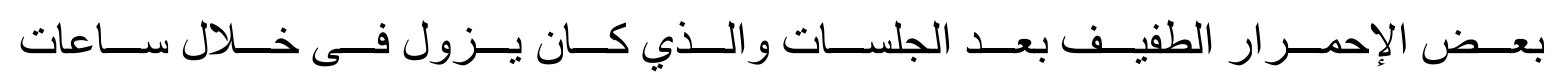

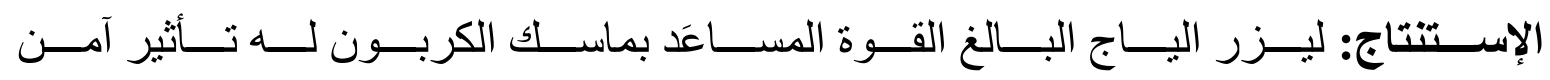

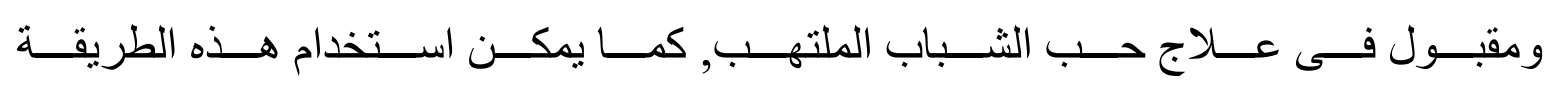

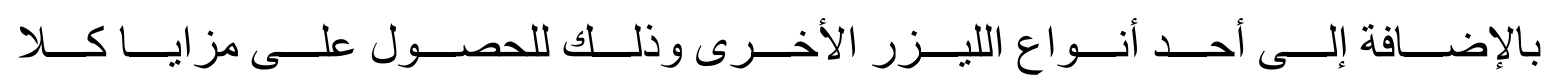
النو عين من الليزر . بلإ.

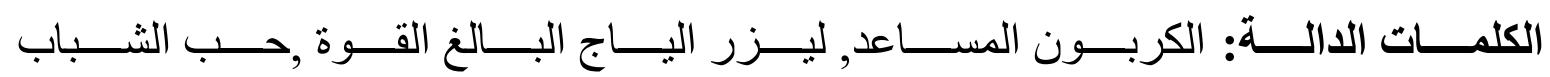
الملتهب. 